\title{
Tecnologias digitais na educação infantil e anos iniciais: estratégias de ensino
}

\author{
Digital technologies in child education and early years: teaching strategies
}

Adriano Edo Neuenfeldt

Doutor em Ensino

Universidade do Vale do Taquari - Univates

Lajeado, RS - Brasil.

adrianoneuenfeldt@universo.univates.br

(i) Derli Juliano Neuenfeldt Doutor em Ciências: Ambiente e Desenvolvimento

Universidade do Vale do Taquari - Univates

Lajeado, RS - Brasil.

derlijul@univates.br

\author{
Manoel Maria Silva Negrão \\ Especialista em Gestão Escolar \\ Governo do Estado do Amapá \\ Macapá, AP - Brasil. \\ manoel.negrao@universo.univates.br
}

\begin{abstract}
Resumo: O distanciamento físico/social provocado pela pandemia do COVID-19 estimulou educadores a repensarem e adaptarem suas práticas pedagógicas. Nesse sentido, essa pesquisa teve como objetivos investigar o uso das tecnologias digitais e formas de trabalhar o medo das crianças frente à pandemia, junto a professores de Educação Infantil e Anos Iniciais. Ressalta-se que o presente estudo buscou subsídios nas percepções de 40 professores da região central do Estado do Rio Grande do Sul/BRA que participaram inicialmente de uma formação continuada e, mediante interesse deles, foram traçadas estratégias de assessoramento para a continuidade das atividades durante a pandemia. Trata-se de uma pesquisa qualitativa, que organizou os dados a partir de questionários impressos e no Google Forms, analisando o conteúdo dos depoimentos dos professores conforme Bardin (2011). Como resultados destacam-se as contribuições dos recursos digitais para articular estratégias de ensino, com reflexões sobre o medo, o uso da literatura infantil e o brincar.
\end{abstract}

Palavras chave educação infantil; tecnologias digitais; COVID-19; ensino.

Abstract: The physical/social distance caused by the COVID-19 pandemic encouraged educators to rethink and adapt their teaching practices. In this sense, this research aimed to investigate the use of digital technologies and ways of working the fear of children facing the pandemic, together with teachers of Child Education and Early Years. It is noteworthy that this study sought subsidies in the perceptions of 40 teachers in the central region of the State of Rio Grande do Sul/BRA who initially participated in continuing education and, upon their interest, strategies were designed to provide advice for the continuity of activities during the pandemic. This is a qualitative research, which organized data from printed questionnaires and Google Forms, analyzing the content of teachers' testimonies according to Bardin (2011). The results highlight the contributions of digital resources to articulate teaching strategies, with reflections on fear, the use of children's literature and playing.

Keywords: child education; digital technologies; COVID-19, teaching.

Cite como

(ABNT NBR 6023:2018)

NEUENFELDT, Adriano Edo; NEUENFELDT, Derli Juliano; NEGRÃO, Manoel Maria Silva. Tecnologias digitais na educação infantil e anos iniciais: estratégias de ensino. Dialogia, São Paulo, n. 40, p. 1-18, e20639, jan./abr. 2022. Disponível em: https://doi.org/10.5585/40.2022.20639.

American Psychological Association (APA)

Neuenfeldt, A. E., Neuenfeldt, D. J., \& Negrão, M. M. S. (2022, jan./abr.) Tecnologias digitais na educação infantil e anos iniciais: estratégias de ensino. Dialogia, São Paulo, 40, p. 1-18, e20639. https://doi.org/10.5585/40.2022.20639. 


\section{Introdução}

A pandemia provocada pelo Coronavírus (SARS-CoV-2) e a doença por ele causada (COVID-19), dada a rapidez da contaminação e da propagação, acarretaram a tomada de medidas de distanciamento físico/social, que também atingiram a educação, inclusive a Educação Infantil e os Anos Iniciais do Ensino Fundamental. Assim, no atual contexto pandêmico, em que se buscam novas formas de ensinar, alguns temas e situações que permeavam a comunidade escolar e que já estavam presentes mesmo antes da pandemia, necessitaram ser ressignificados, entre elas, o uso de tecnologias digitais. O caminho para a ressignificação perpassa pelo professor, que, em pouco tempo, teve que adaptar-se ao ensino mediado pelas tecnologias e mídias digitais, ensinando, por vezes, remotamente e, em outras, hibridamente, intercalando momentos síncronos com assíncronos, bem como, mais recentemente, presencialidade com virtualidade.

Utilizamos o termo ensino remoto, pois, no Rio Grande do Sul, contexto da pesquisa, foi a terminologia que repercutiu e teve visibilidade. Esse termo, de acordo com Santana e Sales (2020), não é contemplado na legislação vigente como tipologia ou modalidade de ensino.

\footnotetext{
No entanto, o termo se popularizou na mídia, nas redes sociais digitais e entre gestores públicos na tentativa de nomear as ações pedagógicas criadas para atender às regulamentações emergenciais emitidas pelos órgãos públicos no que se refere à educação escolar em tempos de pandemia (SANTANA; SALES, 2020, p. 81).
}

O ensino remoto engloba o uso de ambientes virtuais de aprendizagem (AVA), de modo síncrono ou assíncrono, tais como o Moodle ou Google Classroom; o uso das redes sociais, tais como o Facebook, Instagram ou aplicativos como o Whats App, como caminhos para que os temas de estudo cheguem aos estudantes. Já para os alunos sem acesso à internet, é possível a retirada das atividades impressas elaboradas pelos professores na escola, para realizá-las em casa, sozinhos, ou com o apoio de familiares.

Moran (2015, p. 27) define o ensino híbrido nos seguintes termos:

\footnotetext{
Híbrido significa misturado, mesclado, blended. A educação sempre foi misturada, híbrida, sempre combinou vários espaços, tempos, atividades, metodologias, públicos. Esse processo agora, com a mobilidade e a conectividade, é muito mais perceptível, amplo e profundo (MORAN, 2015, p. 27).
}

$\mathrm{O}$ autor reforça que o ensino híbrido não se reduz ao mix presencial e on-line, sala de aula e outros espaços ou ao uso de metodologias ativas. O ensino híbrido diz respeito a uma proposta curricular mais flexível, com tempos e espaços integrados, que combinam momentos virtuais e presenciais. Contudo, para ter êxito, é preciso capacitar os professores, ressalta o autor. 
A pandemia fez emergir, em função da necessidade do momento, um contexto educacional de aprendizagens, adaptações e experimentações didático-pedagógicas. Porém, este estudo tem sua gênese num momento anterior à pandemia, atrelado a um processo de formação continuada que vem sendo desenvolvido com 40 professores da Região Central do Estado do Rio Grande do Sul/Brasil. A partir das necessidades pedagógicas desses professores, foi proporcionada uma formação continuada, que, apesar da pandemia, foi mantida. A proposta foi organizada em duas etapas, a saber: inicialmente, ainda antes da pandemia, mais especificamente no final do segundo semestre de 2019, observou-se o posicionamento dos professores. Na sequência, na fase de acompanhamento, já durante a pandemia, buscou-se conhecer e contribuir com as necessidades advindas desse período.

Essa pesquisa teve como objetivo principal investigar o uso das tecnologias digitais e formas de trabalhar o medo das crianças frente à pandemia, junto a professores de Educação Infantil e Anos Iniciais. A partir dessa investigação, foram compartilhadas estratégias pedagógicas mediadas pelas tecnologias digitais, desenvolvidas para auxiliar esses professores durante o período pandêmico, com potencial para continuarem sendo usadas após o abrandamento da pandemia, no retorno às aulas presenciais.

Assim, entende-se que apresentar inquietações e propiciar reflexões sobre possibilidades didático-pedagógicas na Educação Infantil e nos Anos Iniciais do Ensino Fundamental contribuem para o enfrentamento de situações provocadas durante o período de pandemia do COVID-19. Nesse momento pandêmico, o compartilhamento de pesquisas e experimentações pedagógicas fortalecem o ensino e a coletividade docente.

\section{Caminhos metodológicos}

As informações apresentadas neste artigo fazem parte de uma investigação que iniciou no segundo semestre de 2019 e que ainda está em desenvolvimento, especificamente, no que tange ao compartilhamento de materiais, à coleta de informações e ao assessoramento dos envolvidos no estudo.

Iniciou-se com a participação de 40 professores de Educação Infantil e Anos Iniciais, num curso de formação continuada na região central do Estado do Rio Grande do Sul/Brasil. Para otimizar a coleta de dados e o compartilhamento de informações, esses professores foram organizados em dois grupos de trabalho, de acordo com a afinidade ou a proximidade das escolas em que atuavam. 
O estudo caracterizou-se como uma pesquisa qualitativa, pois, segundo Angrosino (2009, p. 9), a pesquisa qualitativa leva em consideração "o contexto e os casos para entender uma questão em estudo". Como a pesquisa foi desenvolvida num espaço de interlocução com os professores, em alguns momentos, também foi possível identificar características de outras modalidades de pesquisa, como, por exemplo, a pesquisa participante. Brandão e Streck (2006, p. 41) asseveram que o início da pesquisa participante se dá a partir da "realidade concreta da vida cotidiana dos próprios participantes individuais e coletivos do processo, em suas diferentes dimensões e interações.

A coleta de dados foi organizada pelos professores-pesquisadores com base nas interações com os professores, registradas num diário de pesquisa. Conforme Pádua (2012, p. 62), o diário de pesquisa permite “[...] uma retrospectiva do trabalho já realizado. Pode ainda fornecer novos elementos para a análise de aspectos que não tinham sido levados em conta na pesquisa ou mesmo para a exploração de novos recursos que não haviam sido considerados”.

Ainda a respeito da coleta de informações, inicialmente, fez-se uso de um questionário no Google Forms. De acordo com Malheiros (2011, p. 160), questionários on-line "são questionários construídos em sites específicos na internet, nos quais o respondente acessa o site e marca suas opções de resposta. Além do baixo custo, esses questionários facilitam o trabalho de compilação dos dados". Num segundo momento, foram coletadas informações a partir de um questionário impresso, aplicado durante a formação continuada, que, posteriormente, foi digitalizado. Além disso, observou-se a troca de mensagens no Whats $A p p$, a partir da organização dos dois grupos de professores e, por fim, um outro questionário, de acompanhamento, também enviado pelo Google Forms, que ainda está aberto a respostas.

A análise dos dados foi baseada em referenciais como os de Bardin (2011), que propõe algumas etapas de análise, a saber: a pré-análise; a exploração do material; e o tratamento dos resultados, a inferência e a interpretação. Cada depoimento era carregado de mensagens que precisavam ser desveladas. Segundo Bardin (2011, p. 15), trata-se de uma "tarefa paciente de 'desocultação'.

Para resguardar os direitos dos participantes da pesquisa e para que os dados pudessem ser utilizados, todos os cuidados éticos necessários foram realizados. Foi preenchido o Termo de Consentimento Livre e Esclarecido (TCLE), para atestar que os professores concordaram em participar da pesquisa de modo voluntário, na condição de que seus nomes permanecessem no anonimato, sem nenhum tipo de risco ou prejuízo para eles. Além disso, os professorespesquisadores colocaram os seus endereços eletrônicos à disposição para contatos e esclarecimento 
de dúvidas, bem como para ampliar os espaços de diálogo a respeito da formação e dos resultados da pesquisa.

Para resguardar o anonimato e os direitos dos participantes da pesquisa, além do TCLE, os professores foram denominados de prof. 1, prof. 2, prof. 3, e assim por diante.

\section{Discussão dos resultados}

Nesse período de pandemia, os professores da Educação Infantil e dos Anos Iniciais do Ensino Fundamental vêm encontrando dificuldades para ensinar, similares às dos docentes de outros níveis de ensino. Eles estão tentando adaptar o que vinha sendo desenvolvido no ensino presencial ao ensino virtualizado ou híbrido. No entanto, ao dar-se conta de que os professores atendem crianças, há de se considerar atentamente os meios, as tecnologias digitais e a forma de usá-las para interagir. Lorenzetti e Delizoicov (2001, p. 56) afirmam que "o computador por si só não constitui uma atividade significativa. Ele é um meio, um auxiliar, um facilitador do ato pedagógico".

Além do computador, o uso do celular também foi constante nas aulas remotas. Moran (2015) concebe e enfatiza que a inclusão do celular, uma tecnologia móvel, na sala de aula vai além do desenvolvimento tecnológico ou de uma forma de passar o tempo, ou seja, o autor ressalta a necessidade de preparação dos professores para que possam utilizá-lo de forma segura e satisfatória, transformando-o num aliado para a aprendizagem dos alunos:

\footnotetext{
A chegada das tecnologias móveis à sala de aula traz tensões, novas possibilidades e grandes desafios. As próprias palavras "tecnologias móveis" mostram a contradição de utilizá-las em um espaço fixo como a sala de aula: elas são feitas para movimentar-se, para levá-las para qualquer lugar, utilizá-las a qualquer hora e de muitas formas". (MORAN, 2015, p. 1).
}

As crianças que permanecem em casa e recebem as atividades enviadas pela escola necessitam ser acompanhadas nesses espaços, respectivamente, por um responsável ou familiar e por um professor. Assim, mesmo que a internet seja um caminho para a ampliação dos conhecimentos, há a necessidade de um mediador.

Masetto (2017) entende a mediação pedagógica como uma atitude, uma investida do professor como incentivador da aprendizagem, que estabelece pontes entre o estudante e seu processo de aprendizagem, não de forma estanque, parada, mas uma ponte que se movimenta de forma ativa e colaborativa, para que o aluno atinja seus objetivos. Com a postura de mediação intencional, planejada, característica da educação formal, as potencialidades da aprendizagem remota se ampliam. 
Dessa forma, considera-se relevante o papel do professor, pois "caberá ao professor, juntamente com os alunos, localizar as fontes de informação, proporcionando situações nas quais possam interagir com outras fontes de informação" (LORENZETTI; DELIZOICOV, 2001, p. 56). No entanto, além das questões tecnológicas que propiciam o acesso, é necessário atentar para que os temas abordados sejam potencialmente significativos para as crianças. Entre esses temas, destaca-se, por exemplo, a questão do medo provocado pela pandemia.

Algumas redes de ensino, em virtude da suspensão das aulas presenciais por causa do contexto pandêmico e para abrandar a defasagem no aprendizado, trabalharam em regime de colaboração com os municípios, estruturaram a flexibilização curricular, chamado de currículo prioritário, com base no referencial da Base Nacional Comum Curricular (BNCC) e propuseram a priorização de habilidades essenciais a serem trabalhadas nas atividades pedagógicas não presenciais.

Nesse aspecto, percebe-se que, apesar das limitações impostas pela pandemia, os professores estão buscando complementar a sua formação inicial, mesmo que seja em formações online, a partir do auxílio de colegas ou por iniciativa própria, por meio de pesquisas sobre formas de ensinar. De acordo com Demo (2010, p. 51), “o ambiente de estudo e pesquisa não é fomentado, em parte, porque o professorado não pesquisa nem elabora. Só dá aula”. Contudo, o contexto da pandemia exigiu tanto da parte dos gestores educacionais quanto dos professores uma postura investigativa, pois as metodologias de ensino presenciais necessitaram ser adaptadas e (re)contextualizadas para dar conta do novo cenário educacional.

Nesse contexto, a seguir, apresentamos os resultados que se relacionam ao processo formativo dos professores com base na análise das fases da coleta de dados, as quais foram organizadas de dois modos: a fase inicial, antes da pandemia, e a fase de acompanhamento, que ainda está em andamento. Por fim, o compartilhamento de estratégias de ensino e aspectos evidenciados como relevantes, a partir das percepções dos professores.

\section{Fase inicial}

$\mathrm{Na}$ primeira fase, apresentam-se questões relativas ao uso das tecnologias digitais e como os professores abordavam questões relativas ao medo. Percebe-se, a partir dos depoimentos do Quadro 1, que, quanto aos recursos digitais, sobressai o vídeo como mídia digital mais utilizada. 
Quadro 1 - Depoimentos de professores sobre o uso de ferramentas digitais

\begin{tabular}{|c|c|}
\hline & $\begin{array}{l}\text { Dentro de sua prática de ensino, qual(is) recursos(s) tecnológico(s) você } \\
\text { utiliza, qual a importância dela(s) na sua atuação e com que frequência é(são) } \\
\text { usada(s)? }\end{array}$ \\
\hline Prof. 1 & Vídeos, filmes e pesquisas na internet. \\
\hline Prof. 2 & Internet para pesquisas e estudos \\
\hline Prof. 3 & $\begin{array}{l}\text { Celular, sala de multimídia, computadores e data show. São importantes como } \\
\text { recursos para deixar mais atraente as aulas ou conteúdo. Quase toda a semana se } \\
\text { utiliza. }\end{array}$ \\
\hline Prof. 4 & $\begin{array}{l}\text { Sou aluna da Pedagogia/UFSM, no curso tivemos uma disciplina " Tecnologia da } \\
\text { Informação e comunicação aplicadas a educação" abordou uso de ferramentas } \\
\text { tecnológicas, onde tivemos que fazer um pequeno vídeo, e apresentar. Muito pouco } \\
\text { de prática, muita teoria, sendo que eu e colegas sentimos dificuldades na execução } \\
\text { mesmo com todo acesso à informação que hoje temos. }\end{array}$ \\
\hline Prof. 5 & Uso o DVD, para assistirmos filmes e ouvir músicas, uso de 2 a 3 vezes na semana. \\
\hline Prof. 6 & Eu utilizo a Internet para pesquisar atividades no meu trabalho. \\
\hline Prof. 7 & $\begin{array}{l}\text { Utilizo uma vez por semana a televisão ou o aparelho de datashow na sala de aula para } \\
\text { apresentar algum vídeo com enfoque ao conteúdo. Em uma oportunidade os alunos } \\
\text { fizeram desenhos através da sombra refletida pela luz do datashow. Esta atividade } \\
\text { causou grande surpresa entre eles. Foi algo diferente que os alegrou em realizar. } \\
\text { Acredito que as mídias e novas tecnologias são ferramentas importantíssimas para } \\
\text { auxiliar no desenvolvimento da criatividade dos alunos. }\end{array}$ \\
\hline Prof. 8 & Pesquiso o tema que trabalhei em sala de aula, vídeos sobre o tema, filme. \\
\hline Prof. 9 & $\begin{array}{l}\text { Já contei histórias nos computadores, com o celular já utilizei vídeo de algum assunto } \\
\text { que surgiu na rodinha, também utilizo o celular para as músicas. }\end{array}$ \\
\hline Prof. 10 & Assistir desenhos animados e trabalhar com sobras e luzes. \\
\hline Prof. 11 & Vídeos, som, computadores. \\
\hline Prof. 12 & Celular (foto, vídeo, bluetooh), computador e datashow (vídeos, filmes, slides). \\
\hline Prof. 13 & Vídeos e músicas. Ouvir histórias. \\
\hline Prof. 14 & $\begin{array}{l}\text { A tecnologia usada na escola é o vídeo. Quando trabalho assunto que tem } \\
\text { necessidade de assistir um filme coloco a eles para o melhor entendimento. }\end{array}$ \\
\hline Prof. 15 & $\begin{array}{l}\text { Muito pouco uso. Alguns vídeos e alguma pesquisa pelo fato de não temos net nas } \\
\text { salas, somente secretaria. }\end{array}$ \\
\hline
\end{tabular}

Fonte: Dos autores.

Além dos vídeos, percebe-se, mesmo que de forma tímida, que um número pequeno de professores desenvolve alguma atividade específica usando o celular, para reforçar um assunto/conteúdo/atividade do componente curricular ou criar grupos de comunicação e de 
interação com os alunos em determinado projeto escolar. Assim como qualquer outra tecnologia digital móvel, o celular pode auxiliar e favorecer o estreitamento entre professores e alunos, auxiliando no processo de ensino e aprendizagem, facilitando o contato entre ambos, diminuindo a distância entre os envolvidos no processo educacional. No entanto, está mais presente em atividades no Ensino Médio e bem menos nos Anos Iniciais do Ensino Fundamental $\left(1^{\circ}\right.$ ao $5^{\circ}$ ano). Porém, cabe lembrar, concordando com Moran (2015), que o papel do professor é fundamental no ensino mediado pelas tecnologias.

Quanto às dificuldades no uso dos recursos digitais, exemplificados abaixo no Quadro 2, constata-se que, no grupo de professores, há quem não tem aparelho; outros têm dificuldades de acesso a suportes técnicos e à internet, além dos que têm dificuldades para incorporar as tecnologias digitais e seus recursos de modo regular no planejamento das aulas.

Quadro 2 - Depoimentos de professores a respeito das dificuldades do uso de ferramentas digitais

\begin{tabular}{|c|c|}
\hline & $\begin{array}{l}\text { Que dificuldade(s) você encontra no uso do(s) recursos(s) } \\
\text { tecnológico(s) que você citou anteriormente? }\end{array}$ \\
\hline Prof. 1 & $\begin{array}{l}\text { De baixar da internet. Sinal fraco da net na escola e computadores com } \\
\text { problemas no laboratório de informática. }\end{array}$ \\
\hline Prof. 2 & Pouca habilidade em certos programas. \\
\hline Prof. 3 & Gostaria de saber mais para poder explorar mais. \\
\hline Prof. 4 & $\begin{array}{l}\text { Deveria ser disponibilizado desde o início do curso a aprendizagem destes } \\
\text { recursos, o que muito agregaria nos planejamentos de aula e execução. }\end{array}$ \\
\hline Prof. 5 & Nenhuma. \\
\hline Prof. 6 & Não ter Internet na sala de aula. \\
\hline Prof. 7 & Como apresento vídeos prontos, não encontro dificuldades. \\
\hline
\end{tabular}

Fonte: Dos autores.

Entretanto, os depoimentos dos professores evidenciam que não há unanimidade quanto ao uso e à importância das tecnologias digitais, mas há interesse e encaminhamentos para o uso. De acordo com Martino (2017, p. 28),

[...] as transformações da tecnologia permitem um acesso cada vez maior às redes de computadores. Quanto mais o ciberespaço se expande, maior o número de indivíduos e grupos conectados gerando e trocando informações, saberes e conhecimentos. Além disso, cria as condições, na cibercultura, para que novos saberes sejam desenvolvidos aplicativos, sites, programas, e assim por diante. 
Anjos e Francisco (2021, p. 130) compartilham que "[...] a literatura aponta o uso responsável das tecnologias pelas crianças pequenas, o que implica a necessidade de acompanhamento e supervisão, com controle do tempo de exposição às telas por parte de pais/mães e cuidadores". Esses mesmos autores ressaltam que o uso das tecnologias para e com as crianças depende de um trabalho conjunto com as escolas: "Entretanto, quando a discussão passa a ser feita em termos institucionais, o campo não é mais apenas de escolha das famílias, mas também das instituições educacionais que precisam refletir a respeito dos interesses e das necessidades envolvidas no uso" (ANJOS; FRANCISCO, 2021, p. 130).

Desta feita, o professor que propõe o ensino mediado pelas tecnologias para este nível de ensino precisa dispor, além do normal, do apoio das famílias, para acompanhar diariamente as atividades educacionais propostas, pois se configuram de forma diferente das aulas remotas realizadas nos Anos Finais do Ensino Fundamental ( $6^{\circ}$ ao $9^{\circ}$ ano $)$ e do Ensino Médio, cujos alunos possuem maior autonomia.

Quadro 3 - Depoimentos de professores sobre a abordagem do medo

\begin{tabular}{|c|c|}
\hline & Como você aborda a questão do medo com os seus alunos? \\
\hline Prof. 1 & Dialogando da necessidade de enfrentá-los. \\
\hline Prof. 2 & $\begin{array}{l}\text { Ainda não trabalhei nada neste sentido por não surgir ainda o foco neste } \\
\text { assunto. }\end{array}$ \\
\hline Prof. 3 & $\begin{array}{l}\text { Geralmente por meio de histórias com temas parecidos que fazem os } \\
\text { educandos refletirem. }\end{array}$ \\
\hline Prof. 4 & $\begin{array}{l}\text { Este é um tema bastante complexo e importante de ser trabalhado em sala de } \\
\text { aula. Pois em nossa vida quem não teve medo ou medos diante de certas } \\
\text { situações e ou pessoas. Para ser abordado requer muita compreensão em qual } \\
\text { contexto a criança está imersa. Muito diálogo e amorosidade para que se possa } \\
\text { ter a confiança de dialogar com os alunos e todo o contexto escolar. }\end{array}$ \\
\hline Prof. 5 & $\begin{array}{l}\text { Eu converso sobre o medo, explico que não precisa ter medo daquele animal } \\
\text { ou personagem, que temos que cuidar deles, pois eles têm medo também é } \\
\text { que temos que ser amigos. }\end{array}$ \\
\hline Prof. 6 & Eu abordo de forma lúdica porque são muito pequenos. \\
\hline Prof. 7 & Apenas com diálogos. Ainda não fiz nenhum projeto referente ao tema. \\
\hline Prof. 8 & $\begin{array}{l}\text { Geralmente trago um filme, vídeo ou texto, história. A partir de cada situação } \\
\text { procuro trabalhar. Conversar em rodinha no grande grupo para contar o } \\
\text { medo. }\end{array}$ \\
\hline
\end{tabular}




\begin{tabular}{|l|l|}
\hline Prof. 9 & $\begin{array}{l}\text { Vou começar a trabalhar sentimentos na próxima semana por uma } \\
\text { necessidade que surgiu e que até então não tinha aparecido para ser trabalhado } \\
\text { anes. Vou começar com o livro dos monstros na minha. }\end{array}$ \\
\hline Prof. 10 & Ainda não trabalhei com este assunto. \\
\hline Prof. 11 & $\begin{array}{l}\text { Propor a criança reflexão, autoconhecimento, através da escuta a criança nos } \\
\text { demonstra esses sentimentos cabe ao educador valorizar e dar este suporte } \\
\text { para que aconteça esse processo de valorização de habilidades } \\
\text { socioemocionais. }\end{array}$ \\
\hline Prof. 12 & $\begin{array}{l}\text { Auxiliando o processo da compreensão e de como lidar com esse sentimento. } \\
\text { Prof. 13 }\end{array}$ \\
$\begin{array}{l}\text { Através de jogos, relacionado aos sentimentos através de histórias com } \\
\text { fantoches. }\end{array}$ \\
\hline Prof. 14 & \begin{tabular}{l} 
Literaturas, músicas, desafios, brincadeiras. \\
\hline Prof. 15
\end{tabular} Ainda não trabalhei com este tema. \\
\hline
\end{tabular}

Fonte: Dos autores.

Nesse momento de retorno para a presencialidade, para a escola, é importante que o professor lembre as palavras de Freire (2016), ao dizer que ensinar exige saber escutar: “O educador que escuta aprende a difícil lição de transformar o seu discurso, às vezes necessário ao aluno, em uma fala com ele" (FREIRE, 2016, p. 11). Escutar vai além da possibilidade auditiva de cada um, isto é, diz respeito à disponibilidade do sujeito que escuta para a abertura à fala do outro, ao gesto, às diferenças, nos diz o autor. Logo, a escuta na Educação infantil e Anos Iniciais pode partir de diferentes estratégias, mencionadas pelos professores: literatura, músicas, brincadeiras, diálogo..., mas é necessário que ela aconteça permanentemente.

\section{Fase de acompanhamento}

$\mathrm{Na}$ fase de acompanhamento, durante a pandemia, em 2021, foi enviado um outro questionário pelo Google Forms, que ainda está recebendo respostas, com o objetivo de analisar as percepções dos professores em relação às imposições da pandemia para o ensino.

$\mathrm{Na}$ primeira questão, constatou-se que, nas práticas pedagógicas dos professores, nesse período de distanciamento físico/social, os dispositivos eletrônicos utilizados com mais frequência para desenvolver atividades e relacionar-se com as crianças (estudantes) foram os computadores e os smartphones. Portanto, percebe-se que houve uma modificação em relação à fase inicial, na qual poucos professores mencionaram o uso dos smartphones. 
Esses resultados aproximam-se da pesquisa, "Resposta educacional à pandemia de COVID19 no Brasil", divulgada em julho, pelo Instituto Nacional de Estudos e Pesquisas Educacionais Anísio Teixeira - Inep (2021), na qual a disponibilização de materiais impressos (livros didáticos, apostilas/atividades) para os alunos foi o que mais aconteceu (92,8\%). Em segundo lugar, aparece a disponibilização de materiais na internet (vídeos, podcasts, publicações em redes sociais, plataformas virtuais e aplicativos para celular), com $80 \%$ de frequência. Verificou-se que as aulas previamente gravadas (assíncronas) pela internet foram acessadas por 55,7\% dos estudantes. Já as aulas realizadas ao vivo (síncronas) com uso da internet obtiveram 42,6\% de frequência por professores e alunos.

A segunda questão investigou os recursos digitais utilizados com mais frequência para desenvolver atividades e relacionar-se com as crianças, destacando-se o uso do Google Meet, do Facebook e do WhatsApp. O ensino por meio do celular, através dos aplicativos de mensagens como o WhatsApp, possibilita assumir um papel inovador na educação, considerando que o funcionamento em rede e o trabalho colaborativo assumem importância especial nesse processo, feito de conectividade, compartilhamento, colaboração, dialogia e interatividade (SILVA, 2017).

A terceira questão desvelou as dificuldades dos professores relacionadas ao uso de dispositivos eletrônicos e ferramentas digitais, entre as quais destacam: as crianças dependem da disponibilidade de familiares para poderem acessar os materiais enviados; falta de acesso à internet, falta de preparo das crianças e dos familiares para utilizar as tecnologias digitais; falta de preparo dos professores para utilizar as tecnologias digitais.

A quarta questão questionou os tipos de auxílios que os professores vêm recebendo nesse período de pandemia para desenvolverem atividades e/ou manusearem dispositivos eletrônicos e/ou recursos digitais. Como possíveis auxílios foram mencionados o compartilhamento de experiências com os colegas professores e o apoio das Secretarias de Educação em cursos online.

Nesse sentido, tanto a terceira quanto a quarta questão remetem para a formação dos professores. Contudo, que tipo de formação pensar num contexto em que o ensino se desconfigurou e a escola física se torna virtual? Um caminho possível é o trabalho coletivo. De acordo com Terra (2004, p. 162), "para os professores, o trabalho coletivo na escola é uma experiência interessante pelo fato de poder planejar com um grupo pequeno e discutir coisas mais específicas de seu entorno". Além disso, em relação à experiência na formação continuada de professores, a autora destaca que o compartilhamento da maneira de dar aula, o planejamento, a avaliação, possibilitaram aos professores construir sua identidade profissional, ampliando assim sua inserção, imersão e compromisso no mundo educacional (TERRA, 2004, p. 162). 
A quinta questão retomou novamente o modo como estão sendo abordados com as crianças, aspectos relacionados aos medos, nesse momento, provocados pela pandemia, pelo distanciamento e pela perda de familiares e conhecidos. Nesse sentido, foram mencionadas atividades com músicas, vídeos da internet e materiais confeccionados pelos professores e enviados às crianças. Incluem-se aqui vídeos relacionados a atividades físicas.

Apesar da obviedade do tema ao observar o atual contexto pandêmico, por que trabalhar de modo recorrente com a questão do medo? Explica-se, quando uma criança pergunta aos pais ou mesmo ao professor de turma por videoconferência, (como foi o caso do filho de um dos pesquisadores), se pode ir ou retornar à escola, e a resposta obtida de modo simplificada é de que ainda não seria possível por causa do COVID, percebe-se que essa questão se torna atual e precisa ser cuidadosamente explorada e articulada.

De acordo com Pedroso (2004, p. 31): “A elaboração do medo pode também permitir que a criança perceba que não é a única a senti-lo, que o medo é um sentimento perfeitamente superável, do qual não precisa envergonhar-se". A falta da compreensão do todo, pode levar as crianças a associarem a escola ao COVID. Por uma questão de raciocínio lógico, se o COVID está lá fora e a escola é parte desse lá fora, ele poderia estar na escola, consequentemente pode-se criar uma fobia da escola.

Educadores já vem trabalhando com o tema do medo, mesmo antes da pandemia, seja por intermédio de vídeos ou literatura infantil, ou estratégias combinadas. A própria BNCC abre espaço para o tema seja explorado uma vez que esboça preocupação No entanto, nesse momento, precisaram se adequar ainda às tecnologias e mídias digitais. Não se compreendeu o medo como algo ruim, pois em certos momentos ele pode auxiliar na tratativa de algumas questões, como é o caso do COVID, mas em (re)pensar estratégias de ensino para contribuir com o tema. Como asseveram Ostacheveski e Verenka (2004, p. 82): “O medo faz parte do processo de desenvolvimento humano e por isso não pode ser abordado somente pelo seu caráter negativo, pois também pode ser considerado como uma das condições naturais para o desenvolvimento integral da criança”. Cabe ressaltar que, a própria BNCC abre espaço para o tema possa ser abordado. No campo das experiências, "o eu, o outro e o nós", tem como um dos objetivos de aprendizagem e de desenvolvimento "demonstrar empatia pelos outros, percebendo que as pessoas têm diferentes sentimentos, necessidades e maneiras de pensar e agir” (BRASIL, 2017, p. 45).

A sexta questão focou a receptividade das crianças no processo de virtualização de aulas remotas e/ou de ensino híbrido. A resposta que sobressaiu foi que as crianças não conseguem prestar atenção nas aulas por muito tempo. 
A partir dessas respostas, foram desenvolvidas estratégias de ensino mediadas pelas tecnologias digitais, que visaram auxiliar os professores na sua prática pedagógica. Sobre elas tratamos a seguir.

\section{Estratégias de ensino}

Após a primeira fase e durante a fase de acompanhamento, foram organizadas algumas estratégias, entre as quais ressaltam-se: a postagem de materiais num blog; a criação de dois grupos no Whats App e a criação de um canal no YouTube.

- Blog: Para que os professores pudessem acessar e compartilhar materiais, foram disponibilizados livros infantis e personagens feitos de papel e outros materiais. Nesse sentido, foi utilizado um blog de um dos pesquisadores já existente, denominado Oficinas Pedagógicas.

- Grupos de WhatsApp: Os grupos no Whats App foram criados com o intuito de estimular as relações e o compartilhamento de materiais entre os professores. Para tanto, foram criados dois grupos, cada um formado por vinte professores reunidos por afinidades e interesses. No final, acabou sendo uma escolha por proximidade de cidades e escolas. Optou-se pela separação em dois grupos para que não houvesse um congestionamento de mensagens.

Os materiais enviados pelos professores-pesquisadores foram os mesmos para os dois grupos. No entanto, cada grupo tinha autonomia para compartilhar os seus próprios materiais. Apesar de os grupos ainda se manterem ativos, com o tempo, diminuiu o número de integrantes. Os professores justificaram a saída, alegando que, no período de pandemia, houve um aumento de novos grupos no Whats $A p$, grupos de família, de trabalho, de escolas, entre outros, tornando-se cansativo dar conta de todos os grupos.

- Canal do YouTube: Durante a pandemia, os vídeos assumiram um papel de relevância. Também foi criado um canal no YouTube, principalmente, para postagens de vídeos com jogos e brincadeiras. Destaca-se que o YouTube oportuniza o uso de várias ferramentas intuitivas para mixagem, sonorização, edição e pós-produção de vídeos, bem como de ferramentas de interatividade, como links para outros vídeos, textos explicativos e comentários de usuários, disponíveis desde 2008 (RIBEIRO, 2013).

A partir desses três canais de informação e de interação, buscou-se atender três pontos essenciais conforme as necessidades e discussões com os professores: a literatura infantil, o brincar e a produção de vídeos.

O primeiro deles procurou atender as necessidades dos professores e das crianças, refletindo sobre a utilização da literatura infantil. Coelho (2000) afirma que 
[...] a literatura infantil é, antes de tudo, literatura; ou melhor, é arte: fenômeno de criatividade que representa o mundo, o homem, a vida, através da palavra. Funde os sonhos e a vida prática, o imaginário e o real, os ideais e sua possível/impossível realização [...]. (COELHO, 2000, p. 27).

Assim, ressalta-se a importância de uma escolha adequada e criteriosa dos livros a serem compartilhados com os professores que, posteriormente, poderiam ser reenviados aos pais para serem lidos, acompanhados de atividades complementares. Além disso, a literatura infantil oportuniza que as crianças transitem por um mundo fantasioso, imaginário, mas também auxilia na abordagem de temas de interesse, como foi o caso do medo sinalizado pelos professores. Amarilha (2012) comenta que

[...] o receptor da história envolve-se em eventos diferentes daqueles que está vivendo na
vida real e, através desse envolvimento intelectual, emocional e imaginativo, experimenta
fatos, sentimentos, reações de prazer ou frustração podendo, assim, lembrar, antecipar e
conhecer algumas das inúmeras possibilidades do destino humano. (AMARILHA, 2012,
p. 19).

Ainda, conforme pontua Coelho (2000, p. 46), a literatura infantil pode servir ao propósito do entretenimento, pois provoca as “[...] emoções, dá prazer ou diverte e, acima de tudo, modifica a consciência de mundo de seu leitor”, e o pedagógico, “[...] como instrumento manipulado por uma intenção educativa". No atual contexto pandêmico, percebe-se que os professores buscam atender aos dois propósitos, por um lado abrandando o distanciamento físico/social, sugerindo temas como, por exemplo, olhares do mundo pela janela, afeto, carinho, como também abordam o medo, como, por exemplo, o medo da perda e da solidão.

O segundo ponto apontado pelos professores e que mereceu a atenção foi o brincar. A pandemia limitou os espaços do brincar. Muitas crianças ficaram enclausuradas nas próprias casas. Sem a presença de outras crianças, o brincar passou a ser compartilhado com a própria família. Conforme Wajskop (1992, p. 100), "parte-se da premissa de que o brincar infantil é uma atividade social, interativa e cultural. De uma parte, baseia-se na cultura do mundo adulto, sendo uma forma que a sociedade desenvolveu para socializar seus sucessores”.

Ressalta-se que o brincar, na Base Nacional Comum Curricular (BRASIL, 2017), é destacado como um direito fundamental para a aprendizagem e o desenvolvimento das crianças:

Brincar cotidianamente de diversas formas, em diferentes espaços e tempos, com diferentes parceiros (crianças e adultos), ampliando e diversificando seu acesso a produções culturais, seus conhecimentos, sua imaginação, sua criatividade, suas experiências emocionais, corporais, sensoriais, expressivas, cognitivas, sociais e relacionais. (BRASIL, 2017, p. 36). 
Os professores também necessitaram de brincadeiras que pudessem ser enviadas para as crianças e serem desenvolvidas em parceria com seus familiares. Didonet (2013, p. 211) destaca a importância do papel do professor: "Há, porém, um ator decisivo e fundamental, nesse processo pedagógico, do qual depende a presença e a qualidade do brincar no cotidiano da educação infantil - o professor, a professora".

Além disso, é necessário considerar o brincar como "uma atividade fundamentalmente interativa (criança/objeto, criança/adulto, criança/criança ou grupo, criança/consigo mesma) e, por isso mesmo, lugar de troca, de discussão e construção de regras de convivência" (WAJSKOP, 1992, p. 100).

Portanto, mesmo na pandemia, é interessante incentivar a interatividade, ainda que seja em família. Essa interação também pode ser prazerosa e pedagógica. Para Moyles (2002, p. 21),

[...] o brincar, em todas as suas formas, tem a vantagem de proporcionar alegria e divertimento... desenvolve sentimentos de alegria e prazer: o hábito de ser feliz... Mas o brincar também pode proporcionar uma fuga, às vezes das pressões da realidade, ocasionalmente para aliviar o aborrecimento, e às vezes simplesmente, como relaxamento ou como oportunidade de solidão muitas vezes negada aos adultos e às crianças no ambiente atarefado do cotidiano.

O terceiro ponto diz respeito à utilização de vídeos. Compreende-se que os vídeos podem ser utilizados não somente como fontes de informação, mas também como meios para a produção de conhecimento. Nesse sentido, colaboram as pesquisas desenvolvidas por Neuenfeldt (2020) e Neuenfeldt, Schuck e Rodrigues (2021), que exploram os vídeos como Objetos Digitais de Ensino e de Aprendizagem Potencialmente Significativa (ODEAPSs), uma vez que podem operar com características de objetos de aprendizagem e objetivam alcançar uma aprendizagem potencialmente significativa.

\section{Considerações finais}

O exposto nessa pesquisa permite tecer algumas considerações. A primeira delas é que os professores, apesar da pandemia, mantiveram-se envolvidos com as atividades da escola e buscaram estratégias de ensino para além do espaço da sala de aula. Percebeu-se também que as crianças tiveram que se adaptar às tecnologias digitais; no entanto, nem todas as famílias conseguiram fazer o mesmo, ou pela dificuldade de acesso às tecnologias, ou pela dificuldade de acompanhar e de compreender as atividades enviadas.

Outro aspecto diz respeito às estratégias de ensino. Os professores estão buscando aprimorar os processos de ensino e de aprendizagem a partir da prática, combinando o que era 
desenvolvido no presencial com o que está sendo desenvolvido no remoto. Nesse sentido, as tecnologias assumem papel de relevância e o seu uso e escolha dependem dos envolvidos, professores, crianças e famílias.

As interações, o brincar e as questões relativas ao medo ainda são trabalhadas de modo semelhante ao ensino presencial, ou seja, com livros infantis, músicas e vídeos. O que mudou foi a forma como as atividades passaram a ser enviadas e compartilhadas com as crianças. É importante, portanto, explorar e diversificar esses espaços de compartilhamento, pois nem sempre as partes envolvidas, professor, escola, pais e/ou crianças, conseguirão acessar ou enviar os materiais pelo meio que o outro disponibiliza.

Por fim, a pesquisa se mantém ativa e direcionará o olhar para o período de retorno à presencialidade das aulas, que iniciam no Rio Grande do Sul, a partir do segundo semestre de 2021. Esse momento demanda atenção especial e sugere-se que atividades integradas envolvendo pais, crianças, escola e professores sejam realizadas, ainda que virtualmente.

\section{Referências}

AMARILHA, M. Estão Mortas as fadas? Literatura infantil e prática pedagógica. 9. ed. Petrópolis, RJ: Vozes, 2012.

ANJOS, C. I. dos; FRANCISCO, D. J. Educação infantil e tecnologias digitais: reflexões em tempos de pandemia. Revista Zero-a-Seis, v. 23, n. Especial, p. 125-126. Florianópolis, Universidade Federal de Santa Catarina. Disponível em:

https://periodicos.ufsc.br/index.php/zeroseis/article/view/79007. Acesso em: 05 ago. 2021. DOI: https://doi.org/10.5007/1980-4512.2021.e79007

ANGROSINO, M. Etnografia e observação participante. Porto Alegre: Artmed, 2009.

BARDIN, L. Análise de conteúdo. São Paulo: Edições 70, 2011.

BRANDÃO, C. R.; STRECK, D. R. (orgs.). Pesquisa participante: o saber da partilha. 2. ed. Aparecida, SP: Ideias Et. Letras, 2006.

BRASIL. Base Nacional Comum Curricular. Brasilia: MEC, 2017. Disponível em: http://basenacionalcomum.mec.gov.br/images/BNCC_EI_EF_110518_versaofinal_site.pdf. Acesso em: 10 dez. 2021.

COELHO, N. N. Literatura Infantil: teoria, análise, didática. 7. ed. São Paulo: Moderna, 2000.

DEMO, P. Educação e alfabetização científica. Campinas, SP: Papirus, 2010. (Coleção Papirus Educação). 
DIDONET, V. A política de educação infantil e o brincar. In: SALMAZE, M. A.; ALMEIDA, O. A. Primeira infância no século XXI: direitos das crianças de vier, brincar, explorar e conhecer o mundo. Campo Grande, MS: Ed. Oeste, 2013

FREIRE, P. Pedagogia da autonomia. 54. ed. Rio de Janeiro: Paz e Terra, 2016.

INSTITUTO NACIONAL DE ESTUDOS E PESQUISAS EDUCACIONAIS ANÍSIO TEIXEIRA. Sinopse Estatística do Questionário Resposta Educacional à Pandemia de COVID-19 no Brasil - Educação Básica. Brasília: INEP, 2021. Disponível em: https://www.gov.br/inep/pt-br/areasde-atuacao/pesquisas-estatisticas-e-indicadores/censo-escolar/. Acesso em: 10 ago. 2021.

LORENZETTI, L.; DELIZOICOV, D. Alfabetização científica no contexto das séries iniciais. Revista Ensaio - Pesquisa em Educação em Ciências, v. 3, n. 1, p. 45-61, jan./jun., 2001. Disponível em: http://www.scielo.br/pdf/epec/v3n1/1983-2117-epec-3-01-00045.pdf. Acesso em: 9 set. 2018.

MALHEIROS, B. T. Metodologia da pesquisa em educaşão. Rio de Janeiro: LTC, 2011. (Educação).

MARTINO, L. M. S. Teoria das Mídias Digitais: linguagens, ambiente, redes. 2. ed., Petrópolis, RJ: Vozes, 2017.

MASETTO, Marcos. Mediação Pedagógica e Tecnologias de Informação e Comunicação. In: Novas Tecnologias e Mediação Pedagógica. Campinas, SP: Papirus, 2017.

MORAN, J. M. Mudando a educação com metodologias ativas. In: SOUZA, C. A. de; MORALES, O. E. T. (orgs.). Coleção Mídias Contemporâneas - Convergências Midiáticas, Educação e Cidadania: aproximações jovens. Vol. II. PG: Foca-Foto-PROEX/UEPG, 2015. p.15-33. Disponível em: http:/ / uepgfocafoto.wordpress.com. Acesso em: 30 out. 2020.

MOYLES, J. R. Só brincar? o papel do brincar na Educação Infantil. Porto Alegre: Artmed, 2002.

NEUENFELDT, A. E. Produção de Videos como Objetos Digitais de Ensino e de Aprendizagem Potencialmente Significativos (ODEAPSs) nas Ciências Exatas: limites e possibilidades. 2020. Monografia (Doutorado) - Curso de Ensino, Universidade do Vale do Taquari - Univates, Lajeado, 06 mar. 2020. Disponível em: http://hdl.handle.net/10737/2843. Acesso em: 22 nov. 2020 .

NEUENFELDT, A. E.; RODRIGUES, A. W. da L.; SCHUCK, R. J. Produção de vídeos para o ensino: uma proposta possível. In: SILVA, J. S. da et al. (org). Práticas de ensino investigativas da educação infantil à pós-graduação. Lajeado, RS: Editora Univates, 2021. p. 65-74.

OSTACHEVSKI, E. M.; VERENKA, M. S. Chica, a menina que tinha medo de tudo! In: SILVA, M. B. da (org.). Medo, medinhos, medonhos: lidar com o medo infantil. Ijuí, RS: Editora Unijuí, 2004. p. 75-99.

PÁDUA, E. M. M. de. Metodologia da pesquisa: abordagem teórico prática. 17. ed. Campinas, SP: Papirus, 2012. 97 p. (Coleção Magistério: formação e trabalho pedagógico).

PEDROSO, R. de J. O medo infantil e as narrativas. In: SILVA, M. B. da (org.). Medo, medinhos, medonhos: lidar com o medo infantil. Ijuí, RS: Editora Unijuí, 2004. p. 19-42. 
RIBEIRO, Â. A. YouTube, a nova tv corporativa: O vídeo na web como estratégia de comunicação. Florianópolis: Combook, 2013.

SANTANA, C. L. S. E; SALES, K. M. B. Aula em casa: Educação, tecnologias digitais e pandemia COVID-19. Interfaces Cientificas, Aracaju, v. 10, n. 1, p. 75-92, 2020. Disponível em: https://periodicos.set.edu.br/educacao/article/view/9181/4130. Acesso em: 04 set. 2020. DOI: https://doi.org/10.17564/2316-3828.2020v10n1p75-92

SILVA, M. Paulo Freire, Vygotsky, Freinet, Dewey e Anísio Teixeira usariam o Whats App! In: PORTO, C.; OLIVEIRA, K, E.; CHAGAS, A. (orgs.). Whats App e Educação: entre mensagens, imagens e sons. Salvador, BA: EDUFBA, Editus, 2017. p. 15-26.

TERRA, D. Orientação do trabalho colaborativo na construção do saber docente: a perspectiva do planejamento coletivo do trabalho pedagógico (PCTP). Movimento, Porto Alegre, v. 10, n. 1, p. 157-179, jan./abr. de 2004.

WAJSKOP, G. Brinquedoteca: espaço permanente de formação de educadores. In: FRIEDMANN, A. et al. O direito de brincar: a brinquedoteca. São Paulo: Scritta, ABRINQ, 1992. 